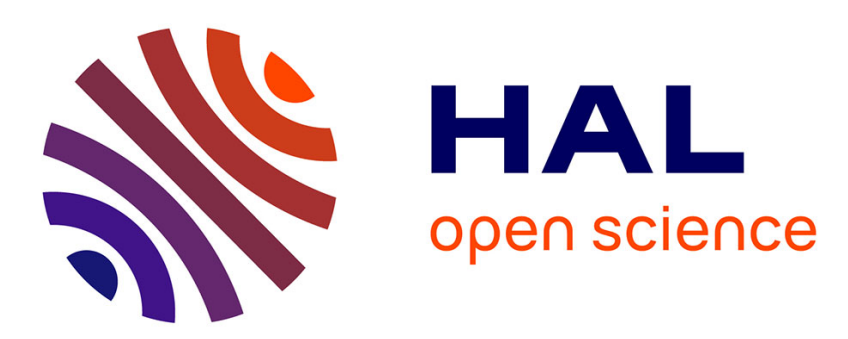

\title{
Effect of the hydrogen tunnelling states of the acoustic wave propagation in niobium at low temperatures
}

\author{
G. Bellessa
}

\section{To cite this version:}

G. Bellessa. Effect of the hydrogen tunnelling states of the acoustic wave propagation in niobium at low temperatures. Journal de Physique Lettres, 1983, 44 (10), pp.387-391. 10.1051/jphyslet:019830044010038700 . jpa-00232207

\section{HAL Id: jpa-00232207 https://hal.science/jpa-00232207}

Submitted on 1 Jan 1983

HAL is a multi-disciplinary open access archive for the deposit and dissemination of scientific research documents, whether they are published or not. The documents may come from teaching and research institutions in France or abroad, or from public or private research centers.
L'archive ouverte pluridisciplinaire HAL, est destinée au dépôt et à la diffusion de documents scientifiques de niveau recherche, publiés ou non, émanant des établissements d'enseignement et de recherche français ou étrangers, des laboratoires publics ou privés. 
Classification

Physics Abstracts

$61.70 \mathrm{~B}-62.65-63.20 \mathrm{M}-63.20 \mathrm{P}$

\title{
Effect of the hydrogen tunnelling states of the acoustic wave propagation in niobium at low temperatures
}

\author{
G. Bellessa \\ Laboratoire de Physique des Solides (*), Bâtiment 510, Université Paris-Sud, 91405 Orsay, France
}

(Reçu le 7 mars 1983, accepté le 29 mars 1983)

\begin{abstract}
Résumé. - La variation de la vitesse du son à $200 \mathrm{MHz}$ a été mesurée jusqu'à $50 \mathrm{mK}$ dans des monocristaux de niobium contenant de l'oxygène et de l'hydrogène. Un effet des défauts tunnel de l'hydrogène sur la vitesse du son est révélé et les paramètres caractéristiques de ces défauts en sont déduits.
\end{abstract}

\begin{abstract}
The variation of the sound velocity at $200 \mathrm{MHz}$ has been measured down to $50 \mathrm{mK}$ in single crystals of niobium doped with oxygen and hydrogen. An effect of the hydrogen tunnelling states on the sound velocity is reported. Some characteristic parameters of these states are then deduced.
\end{abstract}

There is now a lot of experimental evidence for hydrogen tunnelling in niobium. Specific heat [1], thermal conductivity [2,3] and anelastic relaxation [4] exhibit some unusual properties which are well explained with tunnelling motions of hydrogen trapped by either oxygen or nitrogen. The presence of these two last species is necessary for the observation of the hydrogen tunnelling $[4,5]$. Recently inelastic neutron scattering measurements have also been explained with tunnelling of hydrogen trapped with oxygen [6]. I report in this letter sound velocity measurements at low temperatures in niobium doped with oxygen and hydrogen. These measurements reveal a behaviour which has, to my knowledge, never been reported before and which is very significant of the existence of tunnelling states. Some characteristic parameters of these states are then deduced.

In order to explain the specific heat measurements in amorphous materials, Anderson et al. [7] and Phillips [8] have proposed a model which is based on the existence of tunnelling states, also called two-level systems. These systems are described as atoms (or groups of atoms) tunnelling between two potential wells. Obviously, this description applies also to tunnelling of the trapped hydrogen atoms between two interstitial sites, which is the subject with which I am dealing here. In the framework of the model of Anderson et al. [7] and Phillips [8], the effect of the tunnelling states on the sound propagation has been considered [9]. At low temperatures, the one-phonon

(*) Laboratoire associé au Centre National de la Recherche Scientifique. 
process is the main interaction between the acoustic beam and the tunnelling states. It leads to a sound velocity variation according to [10]

$$
\frac{\delta V}{V}=-\frac{N M^{2}}{\rho V^{2}} \frac{1}{E} \tanh \left(\frac{E}{2 k T}\right)
$$

where $E$ is the splitting of the two-level systems, $N$ is their density of states, $M$ is the coupling constant between them and the acoustic wave, $\rho$ is the specific mass and $V$ is the sound velocity. The splitting $E$ is given by $[8,9]$ :

$$
E=\left(\varepsilon^{2}+\Delta^{2}\right)^{1 / 2}
$$

where $\varepsilon$ is the asymmetry of the double-well potential and $\Delta$ is the coupling energy between the two wells. Equation (1) is valid for acoustic frequencies much smaller than $E$. In amorphous materials, there is a distribution of splittings rather than a single one. Hence, equation (1) has to be integrated over a large energy range and leads to the well-known temperature dependence :

$$
\frac{\delta V}{V}=\frac{n M^{2}}{\rho V^{2}} \ln \left(\frac{T}{T_{0}}\right) .
$$

I have performed acoustic experiments in monocrystalline niobium doped with oxygen and hydrogen. The object was to reveal a sound velocity variation according to equation (1), due to the hydrogen tunnelling states. The samples were cut into a monocrystalline rod. The orientation of this one was at random. I shall return later to the metallurgical treatments of the samples. The

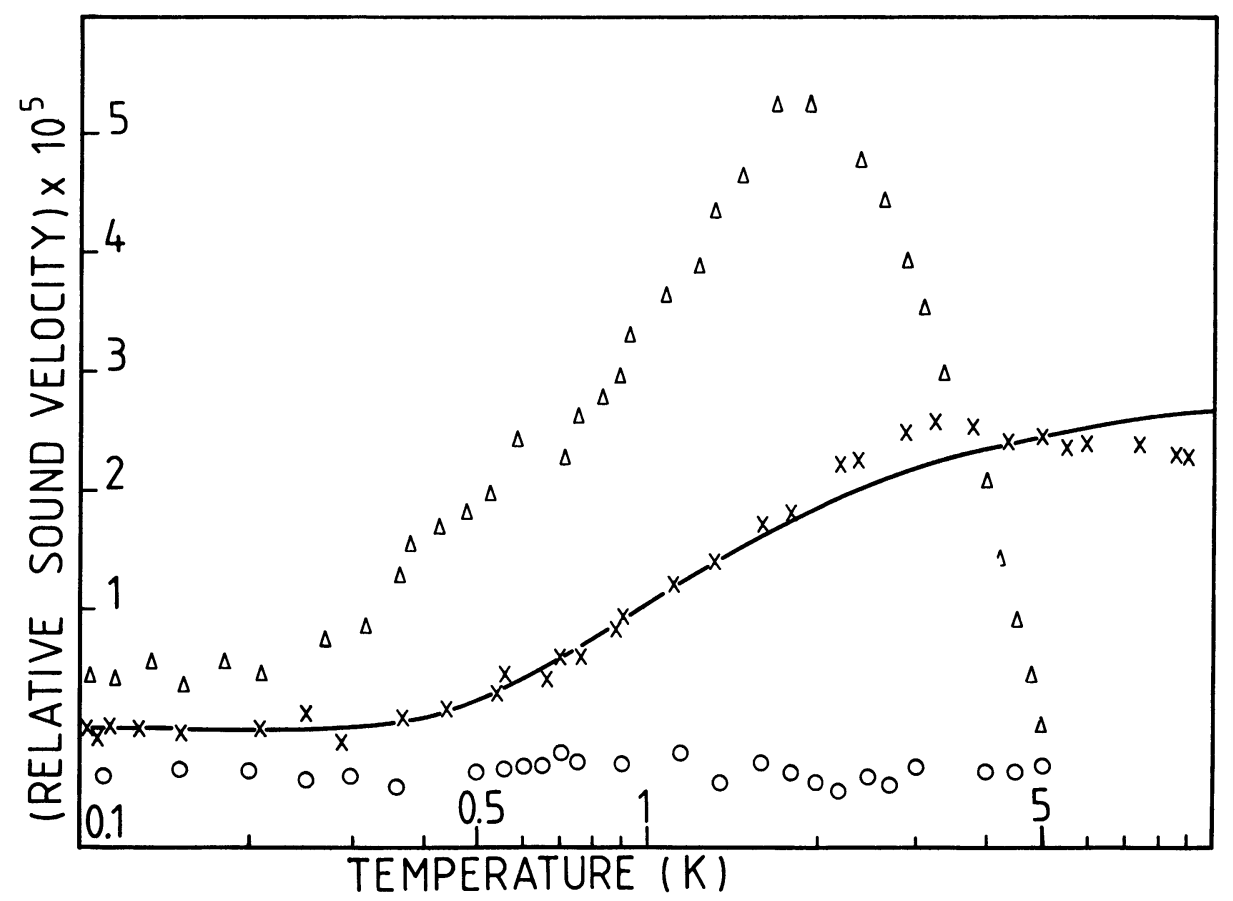

Fig. 1. - Relative velocity of $200 \mathrm{MHz}$ longitudinal acoustic waves as a function of temperature for different samples. The velocity variation is relative to the value at $0.1 \mathrm{~K} \cdot$; the 3 experimental curves are arbitrarily shifted for clarity. $\mathrm{x}, \mathrm{NbO}_{0.0007} \mathrm{H}_{0.017} ; 0, \mathrm{NbO}_{0.008} ; \Delta, \mathrm{NbO}_{0.008} \mathrm{H}_{0.024}$. The solid line is the calculated variation from equation (1). 
sound velocity of longitudinal waves has been measured fown to $50 \mathrm{mK}$. The frequency of the acoustic waves was $200 \mathrm{MHz}$. The measurements were made with a phase comparison method. Hence, only a relative variation of the sound velocity could be measured precisely. The temperature dependence of the sound velocity for 3 different samples are reported in figure 1 . The velocity variation is relative to the value at $100 \mathrm{mK}$. The values between $50 \mathrm{mK}$ and $100 \mathrm{mK}$ are omitted because they are strictly constant. The sample $\mathrm{NbO}_{0.0007} \mathrm{H}_{0.017}$ exhibits a temperature dependence in agreement with equation (1) (I have chosen such a small oxygen doping in order to avoid any stress-induced interaction among neighbouring oxygen-hydrogen pairs). Indeed, the sound velocity is constant between $50 \mathrm{mK}$ and $300 \mathrm{mK}$. Then, it increases up to $3 \mathrm{~K}$ and is again roughly constant up to $9.5 \mathrm{~K}$. The solid line is the calculated variation from equation (1). It appears in figure 1 that the sound velocity in the sample $\mathrm{NbO}_{0.008}$ is constant within $2 \times 10^{-6}$ in the whole temperature range. Lastly, the sample $\mathrm{NbO}_{0.008} \mathrm{H}_{0.024}$ exhibits, at the lowest temperatures, a velocity variation similar to that obtained in $\mathrm{NBO}_{0.0007} \mathrm{H}_{0.017}$. However, above $2 \mathrm{~K}$ the velocity decreases sharply.

Now, I am going to give precise details concerning the sample treatments. The starting material was a monocrystalline rod of $99.99 \%$ - pure niobium and was commercially outgassed in ultrahigh vacuum. It had a residual-resistivity ratio of 100 indicating a content of interstitial nitrogen, oxygen and carbon of about 0.035 at. \% [11]. A sample was cut in this rod and was studied before any treatment. Surprisingly, it exhibited a sound-velocity effect similar to that reported in figure 1 but with a smaller amplitude. The simplest explanation of this behaviour is that the samples, following an ultra-high vacuum treatment, still contained hydrogen. This property has already been reported [12]. In order to suppress any sound-velocity effect, the samples were annealed in an oxygen atmosphere (about $2 \times 10^{-5} \mathrm{mbar}$ ) at $1800^{\circ} \mathrm{C}$ during $16 \mathrm{~h}$. Then, the residual-resistivity ratio was equal to 4 indicating a content of interstitial oxygen of 0.8 at. \% [11]. It appears in figure 1, that such a sample does not exhibit any sound-velocity effect. For hydrogen doping, the samples were put in a sealed tube under a hydrogen pressure $(250 \mathrm{mbar})$ and heated at $700{ }^{\circ} \mathrm{C}$ during about $3 \mathrm{~h}$. The hydrogen content was obtained from the pressure measurements before and after the heat-treatment. The sample $\mathrm{NbO}_{0.008} \mathrm{H}_{0.024}$ was obtained by doping with hydrogen a sample $\mathrm{NbO}_{0.008}$. The sample $\mathrm{NbO}_{0.0007} \mathrm{H}_{0.017}$ was obtained from a sample $\mathrm{NbO}_{n}$ nn8 (which exhibits no sound-velocity effect). The latter was annealed at $1800^{\circ} \mathrm{C}$ during $16 \mathrm{~h}$ in an oxygen atmosphere at a pressure of about $5 \times 10^{-6} \mathrm{mbar}$. At this stage, the residual-resistivity ratio was measured. It was equal to 50 indicating a content of interstitial oxygen of 0.07 at. \% [11]. Then, the sample was charged with hydrogen as above. Because of the excess hydrogen, our samples contained, besides $\mathrm{O}-\mathrm{H}$ pairs, an amount of precipitated hydrogen at low temperatures. However, it is known that tunnelling is not observed for precipitated hydrogen [5].

Experimentally, the sound velocity behaves in the sample $\mathrm{NbO}_{0.0007} \mathrm{H}_{0.017}$ in agreement with the theoretical predictions. In figure 1, the full-line curve is obtained from equation (1). The location of the kink at low temperatures is very sensitive to the $E$ value. The $M$ value, connected with the total velocity variation, is a direct measure of the coupling strength between the tunnelling states and the elastic field. Taking $N=3.9 \times 10^{19} \mathrm{~cm}^{-3}$ (corresponding to the oxygen-hydrogen pair density), $\rho=8.57 \mathrm{~g} / \mathrm{cm}^{3}$ and $V=5.4 \times 10^{5} \mathrm{~cm} / \mathrm{s}$, the best fit is obtained for $E=0.13 \mathrm{meV}$ and $M=13 \mathrm{meV}$ (Fig. 1). Instead of choosing a single splitting value, it would be possible to assume a splitting distribution around a mean value, and to integrate equation (1) over the corresponding energy range. However, this distribution could not be very broad because, if that were the case, the sound velocity no longer would saturate at high temperatures (it is to avoid a strain-induced broadening that the first sample is so weakly doped). The important parameter $\Delta$ cannot be deduced from equation (2), since $\varepsilon$ is unknown. By taking $\varepsilon=0$ (as did Birnbaum and Flynn in their explanation of the specific-heat results [15]), the value $\Delta=0.13 \mathrm{meV}$ is found. It must be pointed out that, if there was a distribution of the energy shifts induced by a strain interaction between the tunnelling states and some defects, then the mean value of $\varepsilon$ would be zero 
and equation (1) integrated over the corresponding energy range would give for $\Delta$ the same value at that above.

The behaviour of $\mathrm{NbO}_{0.008} \mathrm{H}_{0.024}$ containing a large amount of tunnelling states (and also other defects) is reported in figure 1 . The sound velocity varies below $2 \mathrm{~K}$ according to equation (1). Nevertheless, above $2 \mathrm{~K}$ the sharp velocity decrease is inconsistent with equation (1). This behaviour can be explained in two different ways. First, it may arise from the relaxation of the tunnelling states which can be very efficient, because of their large number and which can induce a sharp velocity decrease with increasing temperature [9]. Second, the treatment necessary to obtain a large amount of oxygen-hydrogen pairs leads also to the creation of dislocations [13]. These defects can induce an increase of the sound velocity with decreasing temperature down to $100 \mathrm{mK}$ [14], and thus explain, at least partly, the experimental variation. Lastly, the magnitude of the sound velocity variation is smaller than that expected for the concentration of trapped hydrogen (in comparison with the first-sample results). This behaviour has also been observed in the specific-heat measurements and has been assigned to the possibility of oxygen clustering or trapping at dislocations which reduces the amount of tunnel-active sites [5].

Sound velocity measurements have been made by Poker et al. in the temperature range $0.5 \mathrm{~K}$ to $15 \mathrm{~K}$ on $\mathrm{Nb}-\mathrm{H}$ specimens in which the hydrogen was kept in solution by trapping at oxygen solutes [16]. These authors have reported a small peak in the sound velocity around $2 \mathrm{~K}$. So the velocity decrease that they have observed, can agree with the present results. However their measurements are performed down to $0.5 \mathrm{~K}$ only and they have not observed the kink that we report around $0.4 \mathrm{~K}$ and which is of first importance for the model we have used. Poker et al. interpret their result with relaxation through an Orbach process quite different from the interpretation reported here.

The results reported here are directly comparable with those obtained by Wipf et al. [6]. These authors have performed inelastic neutron scattering measurements on a polycrystalline sample containing 1.3 at. \% of oxygen. They found $\Delta=0.19+0.04 \mathrm{meV}$ which agrees very well with the value deduced here. They did not report any value for $M$.

Now, the question arises about the nature of the tunnelling states. Birnbaum and Flynn have proposed a model assuming that hydrogen atoms tunnel between tetrahedral and triangular sites located on rings [15]. In such a model, all the parameters are known, and it is possible to estimate the off-diagonal matrix element $\Delta$ of the two-well tunnel system [15] :

$$
\Delta \cong \hbar \Omega\left(m d^{2} \Omega / 4 \pi \hbar\right)^{1 / 2} \exp \left(-m d^{2} \Omega / 4 \hbar\right),
$$

where $\Omega$ is the vibration frequency of the hydrogen atom within a well, $m$ is its mass and $d$ is the distance between the two wells. Here $\hbar \Omega \simeq 0.18 \mathrm{eV}$ and $d=0.583 \AA$ is the tetrahedral-triangular site separation. Taking for $m$ the bare mass of the hydrogen atom, equation (4) gives $\Delta \simeq 22 \mathrm{meV}$ which is much larger than the experimental value. This discrepancy may arise from the dressing of hydrogen motion by lattice displacements [15]. Instead of inserting the bare mass in equation (4), an effective mass $m^{*} \simeq 4 m$ is sufficient to suppress this discrepancy.

To conclude, the sound velocity effect allows access not only to the splitting of the tunnelling states but also to the coupling strength between them and the elastic field. Further experiments, particularly in oriented crystals and with different wave polarizations are needed to improve our knowledge of hydrogen tunnelling in b.c.c. metals.

\section{Acknowledgments.}

The author is indebted to Dr. R. Reich for his assistance concerning the metallurgical treatments. He thanks one of the referees for calling his attention to the paper of reference [16]. 


\section{References}

[1] Sellers, G. J., Anderson, A. C. and Birnbaum, H. K., Phys. Rev. B 10 (1974) 2771.

[2] O'Hara, S. G., Sellers, G. S. and Anderson, A. C., Phys. Rev. B 10 (1974) 2777.

[3] Locatelli, M., Neumaier, K. and Wipf, H., J. Physique Colloq. 39 (1978) C6-995.

[4] Chen, C. G. and Birnbaum, H. K., Phys. Status Solidi (a) 36 (1976) 687.

[5] Morkel, C., WiPf, H. and NeumaIer, K., Phys. Rev. Lett. 40 (1978) 947.

[6] Wipf, H., Magerl, A., Shapiro, S. M., Satija, S. K. and Thomlinson, W., Phys. Rev. Lett. 46 (1981) 947.

[7] Anderson, P. W., Halperin, B. I. and Varma, C. M., Philos. Mag. 25 (1972) 1.

[8] Phillips, W. A., J. Low Temp. Phys. 7 (1972) 351.

[9] For a general review see Hunklinger, S. and ARnold, W., Physical Acoustics edited by W. P. Mason and R. N. Thurston (Academic, New York) 1976, Vol. 12, p. 155.

[10] JäCKLE, J., PiChÉ, L., ARnold, W. and Hunklinger, S., J. Non-Cryst. Solids 20 (1976) 365.

[11] Schultz, H., Mater. Sci. Eng. 3 (1968/69) 189.

[12] Maul, M. and Schultz, H., J. Physique Colloq. 42 (1981) C5-73.

[13] The acoustical study of these samples indeed shows some characteristic properties of dislocated lattices.

[14] Alers, G. A., Physical Acoustics, Edited by W. P. Mason (Academic, New York) 1966, Vol. 4A, p. 277.

[15] Birnbaum, H. K. and Flynn, C. P., Phys. Rev. Lett. 37 (1976) 25.

[16] Poker, D. B., Setser, G. G., Granato, A. V. and Birnbaum, H. K., Z. Phys. Chem. 116 (1979) 39. 